\title{
A New Model of International Students' Educational Decision-Making: the Case of Chinese Students' Choices of Major in Accounting in Australia
}

\author{
Haolei Yang \\ Information Technology and Management Department \\ Chengdu Neusoft University \\ Chengdu, China \\ yanghaolei@nsu.edu.cn
}

\begin{abstract}
This study developed a new theoretical framework that may be used to examine the decision-making processes of Chinese students relating to the choice of major into overseas university. Elements from self-determination theory, expectancy-value theory, theory of reasoned action, and research on cultural dimensions have been adapted and incorporated into the theoretical framework. The framework proposes that cultural orientation variables and motivational variables influence the educational decision-making of Chinese students in the choice of accounting major in Australia.
\end{abstract}

Keywords-educational decision-making; culture; motivation; international students; choice of major

\section{INTRODUCTION}

A large number of international students come to Australia from all over the world to study, live and work, which has enriched Australian communities, bring energy, diversity and new ways of seeing things. International students are important to Australia because of their contributions in terms of adding to the diversity of the students' population in Australian higher education institutions. China has been the largest source country by enrolments volume since 2001; in 2012 Chinese students contributed $40.8 \%$ and $29.0 \%$ of Australia's enrolments in the Higher Education sector and in all educational sectors respectively[1] It is important for both Australia and China to get a deeper and more complete understanding of Chinese students' educational choices.

Australia has been suffering from a chronic shortage of suitably qualified accountants so the Australian Federal Government has used skilled migration as a means of mitigating the skills shortage in the accounting profession since more than a decade ago.As a result, surges in the numbers of international students have come to Australia where "Management and Commerce" was the most popular broad field of higher education with more than half of enrolments in 2011[1]. Accounting as a major is chosen by a large mount of Chinese students within Australian universities.

This paper aims to develop a new model to explain the decision-making process associated with the choice of major in accounting by Chinese international students in Australia. Under the frame of this new model, three dominant fields covered in the study: culture, motivation, and decision-making, will be discussed in turn.

\section{CUlture}

\section{A. Culture as General Concept}

Culture is a very complicated concept which has various meanings. In $19^{\text {th }}$ century, Tylor[2]defined the concept of culture as a diverse set of activities characteristic of all human societies, which establish the foundation for the modern understanding of culture. Fan[3]describes culture as "the collection of values, beliefs, behaviors, customs, and attitudes that distinguish a society". One of the most prominent definitions from Hofstede[4]says culture is "the collective programming of the mind that distinguishes the members of one group or category of people from another". It appears most of the definitions agree that culture is a set of shared values, attitudes, goals and practices that characterize a society.

\section{B. Hofstede's five cultural dimensions}

Various approaches use values or value orientations as the criteria for classification of cultures[e.g 4,5].Using value-oriented criteria for classification, Hofstede[4] looks at the cultural dimensions that reflect similarities and differences among cultures. As one of the cultural classification systems, Hofstede's value-based classification system have achieved wide acceptance among scholars in the field of culture, psychology and management.Hofstede[6]developed five cultural dimensions empirically found on a survey he conducted within the IBM Corporation in over fifty countries around the world: (1) power distance, (2) collectivism versus individualism, (3) femininity versus masculinity, (4) uncertainty avoidance, and (5) long-term versus short-term orientation.

The cultural dimension, individualism/collectivism, has been considered as one of the most relevant to notions of vocational development, due to its function of "potentially assesses the degree to which other people, and the self, may have a role in the vocational decisions of individuals"[7]. For the purpose of current research, which focuses on Chinese students' decision-making associated with the choice of major in a cultural orientation context, another vital relevant cultural dimension appears to be Hofstede's long term orientation. 


\section{Individualism Versus Collectivism}

Individualism refers to an orientation toward autonomy and independence; Collectivism refers to an orientation toward relationships and interdependence with others[4]. Individualism/collectivism is perhaps the most important dimension in studying cultural differences[8]. Hofstede explained that the dimension of individualism/collectivism was the degree to which individual decision-making and actions are encouraged by society. According to the study of Fernandez et al.[9], China scored below the mean score of the cultural dimension of individualism/collectivism in total nine countries and can be considered collectivist.

China and most of the other Asian countries are recognized as generally having more allocentrics than idiocentrics. Comparative studies shows that students of Asian backgrounds are substantially more likely to be allocentric than those of European backgrounds[10].

\section{Long Term Orientation}

Hofstede has defined long term orientation as the "fostering of virtues orientated toward future reward, in particular, perseverance, and thrift [4]", while short term orientation was defined as the "fostering of virtues related to the past and present, in particular, respect for tradition, perseveration of 'face', and fulfilling social obligations[4]".

People with a long term orientation may exhibit futurerelated attributes such as planning, hard work, savings, and a willingness to make short-term sacrifices for long-term benefit. Hofstede noted that Chinese culture scored the highest on his scale of long term orientation, followed by Hong Kong, Taiwan, Japan, and South Korea which are all historically rooted in Confucianism[11].

A strong connection appears to exist between an individual's long term orientation and his or her perspectives on education.

\section{Motivation}

Motivation concerns energy, direction, persistence - all aspects of activation and intention. Motivation is valued in the field of psychology because of its consequences: "Motivation produces"[12].In addition to the dimensions of culture described above, elements of three motivational theories, expectancy-value theory, self-determination theory, and the theory of reasoned action are incorporated into the theoretical framework. All of these motivational theories have been shown to be relevant to choice of major decisions [12].

\section{A. Expectancy-Value theory}

Expectancy-value theory (EVT) suggests that the motivation of a person to engage, or not, in a particular activity is determined by both values and future expectancies hold by this person[13], that is to say, that motivation may be predicted by both the expectancy of success in the activity and the values held (e.g. enjoyment, recognition from others, family views, financial rewards etc.). In thecontext of choosingastudy major, individuals who expect to be successful in a particular major, and those who value a particular major, are more likely to choose and expend effort to pursue that major, in comparison to those who do not have such beliefs and values.

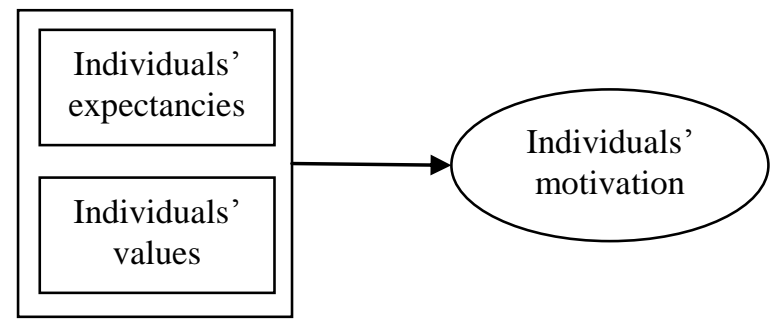

Figure 1. Expectancy-value theory (EVT)

Broad constructs associated with the theory were adapted as:

- Expectancy for educational success: defined as the extent to which one believes that one can be successful in a future major.

- Valuing enjoyment: defined as the valuing of inherent interest or enjoyment in a major.

- Valuing family views: defined as the valuing of opinions from family members with respect to a major.

- Valuing recognition from others: defined as the valuing of recognition from others with respect to a major.

- Valuing desirable occupation: defined as the valuing of desirability of future occupations associated with the chosen major.

- Valuing financial rewards: defined as the valuing of the financial rewards from a future occupation associated with the chosen major.

- Valuing Permanent Residency (PR) status: defined as the valuing of potential migration opportunities to be granted Australian PR visa upon the accomplishment of the chosen major.

All the above elements were incorporated into the theoretical framework associated with other motivational theories, cultural dimensions and decision-making theories.

\section{B. Self-Determination Theory}

Self-determination theory (SDT) is one theory that recognizes that motivation can take various forms along a continuum. At one end of the self-determination continuum is intrinsic motivation, which refers to motivation that is driven by an interest or enjoyment in the task itself, and at the other end is amotivation, which is a lack of motivation[14,15]. In the middle of the self-determination continuum is extrinsic motivation, which is regarded as motivation come from outside of the individual[16].Of relevance to the research reported here, intrinsic/extrinsic motivation appears to be a motivational perspective that is linked to an individual's choice of major.Intrinsic motivation refers to motivation that is driven by an interest or enjoyment in the task itself, and exists within the individual rather than relying on any external pressure [14]. Motivations come from outside of the individual are regarded as extrinsic motivations, which are external rewards like money, trophies, popularity or grades. Extrinsic motivation might also be negative, as is the case 
with coercion or threat of punishment.

Prior studies have dealt specifically with factors associated with the choiceof academic major. Some of the studies in accounting regarding factors influencing choice of major are based on psychological theories. The ideas of intrinsic and extrinsic motivations have been applied in those studies repeatedly to explore the patterns behind student's choice-of-major decision-making process. Strasser, Ozgur, and Schroeder [17] report that students value the interest they have in the major far more important than the career benefits of a major or someone else's influence on them to choose a particular major. An empirical analysis[18] shows that students are most strongly influenced in their choice of major by a genuine interest in the subject matter.However, intrinsic motivation may not necessarily the most import reason for choosing accounting as a major. The survey study by Felton, Buhr, and Northry[19] indicate that students choosing accounting, compared to other business majors place more heavily emphasize long-term earnings and both short-term (e.g., immediate job availability) and long-term (e.g., job security, career flexibility) job market conditions. Besides financial and market conditions, there are other extrinsic factors influencing students to choose or not choose an accounting major. A study conducted by Paolillo and Estes [20]identified that availability of employment was the most important factor for accountants. Moreover, earnings potential, aptitude for the subject matter, and teacher influence also had a greater impact on career-choice for accountants than for the other professional groups. Addition to all the factors described above, prior studies have indicated that the PR factor has a strong impact on the choice of a major in accounting-particularly for international students[21,22]. Considering the big portion of international students studying in Australia are Chinese students, it is important to include the effect of PR into the analysis of current investigation.

\section{Theory of Reasoned Action}

The Theory of Reasoned Action (TRA) was developed and expanded by Ajzen and Fishbein[23]. This theory suggests that a person's behavioral intention (BI) relies on his/her attitude (A) about the behavior and subjective norms $(\mathrm{SN})$, which means $\mathrm{BI}=\mathrm{A}+\mathrm{SN}$. Behavioral intention measures an individual's relative strength of intention to perform behavior. Attitude consists of beliefs about the consequences of performing the behavior multiplied by his/her valuation of these consequences. Subjective norm is referred to as a combination of perceived expectations from relevant individuals or groups along with intentions to comply with these expectations. In other words, a person's attitude, combined with subjective norms, forms his/her behavioral intention. A person's volitional (voluntary) behavior is predicted by his/her attitude toward that behavior and how he/she thinks other people would view them if they performed the behavior. For one's choice-ofmajor decision, the TRA suggests that motivations or the intentions to pursue a particular career path are determined by personal and social influences.

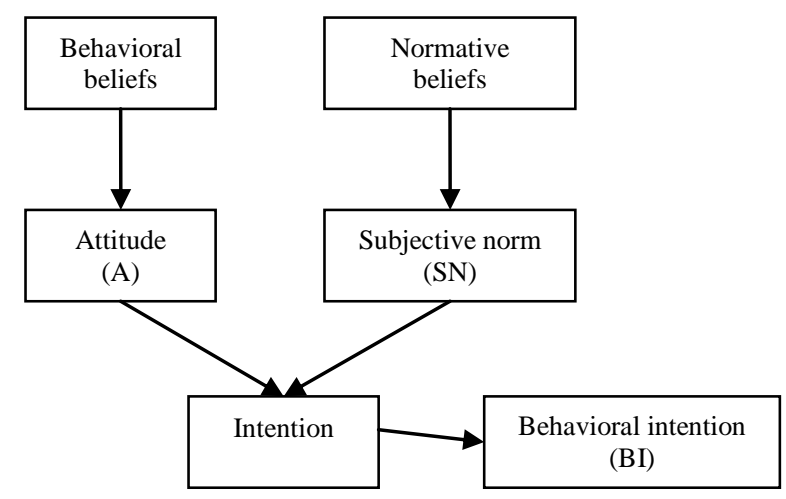

Figure 2. The theory of reasoned action (TRA)

Felton, Buhr, and Northey[19] use the TRA to model the decision whether or not to choose a career in chartered accountancy (CA), compared to other business majors. The primary findings of the study, thanks to RTA, are that CA and non-CA majors report little difference in the relative importance of ten career outcomes (e.g., long-term earnings, job security, structured career path, etc.) but believe there is substantial difference in the likelihood that a career in CA will provide these outcomes.

\section{EDUCATIONAL DECISION-MAKING}

Decision-making may be defined as "commitment to a course of action that is intended to produce a satisfying state of affairs"[24]. The decision-making process can be complex and subject to multiple influences that not only interact with each other but also change over time. This is especially true with major life decisions such as choosing a major for overseas education.

\section{A. Rationaldecision-Making}

Rational decision-making models is organized around selecting the most logical and sensible alternative that would have the desired effect [25]. However, real decision makers are only boundedly rational [26]. Real decision makers must cope with disequilibrium and environmental change, and their uncompleted decision models.

Studies suggest that national or cross-cultural differences exist across entire societies. Martinsons [27] has found that American, Japanese and Chinese business leaders each exhibit a distinctive national style of decision-making. Chia et al. [28] have found the differences of cultural background make students from Australia, Singapore and Hong Kong have distinctive priorities of variables in their career choices.

\section{B. Educationaldecision-making}

Studies show a series of multiple factors, stages and influences impinging on the choice process of educational decision-making. Davies [29] suggests that "education decisions result from a complex relationship between different factors". Easterling[30]details some of these factors: influences on choice of major, purpose-in-life and perceptions of work. Jung [7] makes the point that 
educational decision-making is affected by socioeconomic, family and ethnic cultures. Bloomer and Hodkinson suggest that decision-making is a complex function of which "habitus, personal identity, life history, social and cultural contexts, actions and learning are inter-related"'[31].

Since the complexities and the necessary to take into account the social embeddedness of the educational process, it is reasonable that there is no golden rule about the process of educational decision-making to be found in the literature.

Gambetta [32] views higher educational choice as a result of institutional, economic or cultural constrains over which people have no control. According to his study, education and career decisions are mainly a result of external forces beyond the individual's control. These external forces can be one's cultural background, social class or gender[33]; or influence from others, such as family, friends, or counselor [34]; or the conditions of the nominated occupation, such as job availability and salaries[35]; or the nature of education and training provision, as influenced by government educational policies and the nature of educational institutions[36].

\section{THEORETICAL FRAMEWORK AND CONCLUSION}

The theoretical framework is schematically depicted in Figure 3.

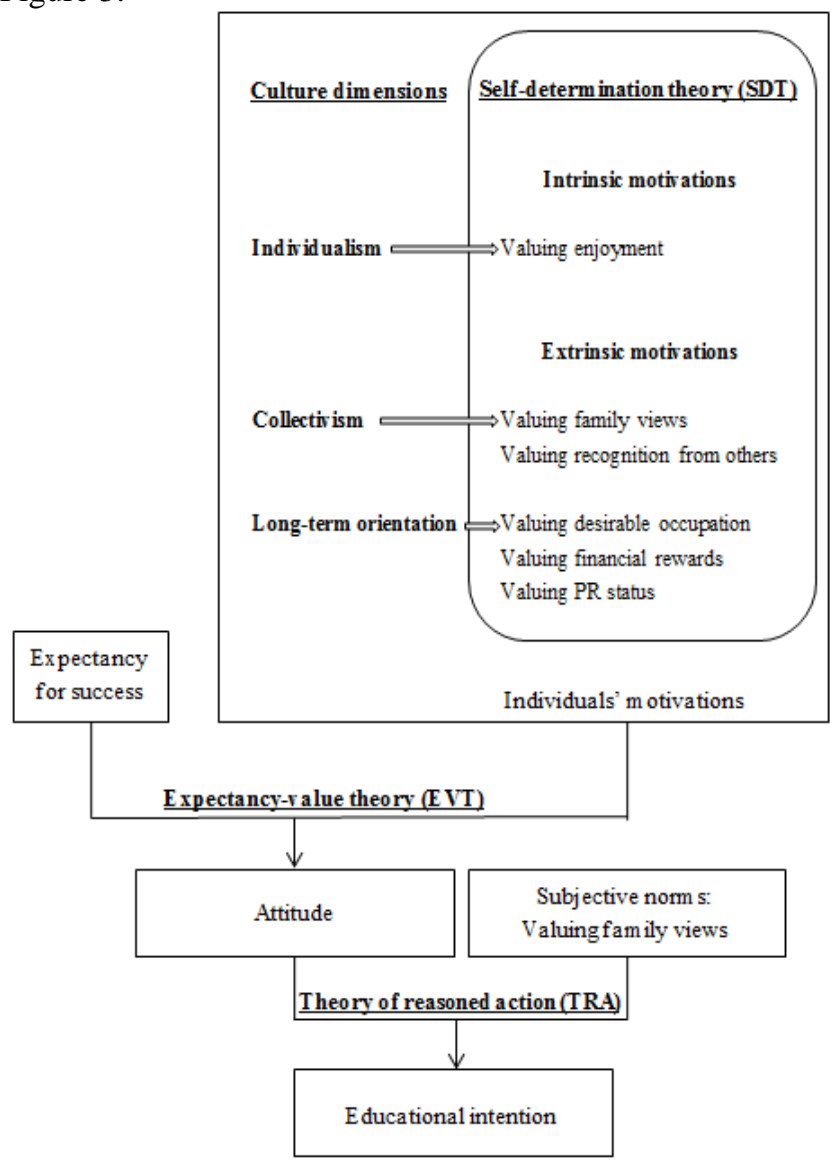

Figure 3. Educational intention framework

Of the cultural orientation variables, dimensions of individualism, collectivism, and long-term orientation followed those of Hofstede (2001). Values, which related to the attractiveness of choice in a certain academic major and motivate one to pursue a career path within it, that hold by the students, were derived from the self-determination theory and expectancy-value theory of motivation.

Reflecting the cultural dimension of individualism and intrinsic motivations, valuing enjoyment was incorporated into the framework. Valuing family views and valuing recognition from others were derived from the collectivism cultural dimension, along with other three variables valuing desirable occupation, valuing financial rewards and valuing PR status which were derived from the cultural dimension of long-term orientation, were incorporated into the theoretical framework as reflections of extrinsic motivations. Another motivational variable of expectancy for success was derived from the expectancy-value theory. Expectancy for educational success refers to belief that one can be successful in a future major.

The remaining constructs in the framework were adapted and derived from the theory of reasoned action. Attitude was conceptualized as personal beliefs about and feelings toward an academic major, while valuing family views, which has been described earlier, was adapted from "subjective social norms", and treated as perceived influences from family members in the choice of future major. Finally, educational intention was conceptualized as the intention to pursue a particular major in the future.

Broadly, the theoretical framework proposed that cultural orientation variables and motivational variables influence the educational decision-making of Chinese students when study overseas in Australia. More specifically, it proposed that individualism, collectivism, and long-term orientation collectively predict the expectancy-value constructs of intrinsic and extrinsic motivations, and expectancy for success with respect to an academic major. In turn, it is proposed that the expectancyvalue constructs along with the cultural orientation variables predict the personal attitudes and subjective social influences of Chinese international students to their choices of future academic area of study in Australia.

This theoretical framework can be used as a guide to examine the cultural and motivational perspectives associated with the educational decision-related process of Chinese students who study overseas.

\section{REFERENCES}

[1] Australian Trade Commission of Australian Government, International Student data for 2012, in, Australian Trade Commission, Canbberra, 2013.

[2] E. Tylor, Origins of culture, Harper \& Row, New York, 1871.

[3] Y. Fan, A classfication of Chinese culture, Cross Cultural Management, 7 (2000) 3-10.

[4] G. Hofstede, Culture's consequences: Comparing values, behaviors, institutions and organizations across nations (2nd ed.), SAGE, Thousand Oaks, CA, 2001.

[5] S.H. Schwartz, A theory of cultural values and implications for work, Applied Psychology: An International Review, 48 (1999) 23-37.

[6] G. Hofstede, Cultures and organizations: Software of the mind, McGraw-Hill International, London, 1994. 
[7] [J.Y. Jung, Culture, motivation, and vocational decision-making of senior high school students, in: Faculty of Arts and Social Siences, University of New South Wales, Sydney, Australia, 2009.

[8] H.C. Triandis, The many dimensions of culture, Academy of Management Executive, 18 (2004) 88-93.

[9] D.R. Fernandez, D.S. Carlson, L.P. Stepina, J.D. Nicholson, Hofstede's country classificiation 25 years later, The Journal of Social Psychology, 137 (1997) 43-51.

[10] T.M. Singelis, H.C. Triandis, D.P. Bhawuk, M.J. Gelfand, Horizontal and vertical dimensions of individualism and collectivism: A theoretical and measerment refinement, Cross-Cultural Research, 29 (1995) 240-275.

[11] G. Hofstede, M.H. Bond, The Confucius connection: From cultural roots to economic growth, Organizational Dynamics, 16 (1988) 5-21.

[12] R.M. Ryan, E.L. Deci, Self-determination theory and the facilitation of intrinsc motivation, social development, and well-being, American Psychologist, 55 (2000) 68-78.

[13] A. Wigfield, J.S. Eccles, Expectancy-value theory of achievemen motivation, Contemporary Educational Psychology, 25 (2000) 68-81.

[14] E.L. Deci, R.M. Ryan, Handbook of self-determination research, University of Rochester Press, Rochester, NY, 2002.

[15] E.L. Deci, R.M. Ryan, Self determination: a macrotheory of human motivation, development and health, Canadian Psychology, 49 (2008) 182-185.

[16] E.L. Deci, R.M. Ryan, Intrinsic motivation and self-determination in human behavior, Plenum, New York, 1985.

[17] S.E. Strasser, C. Ozgur, D.L. Schroeder, Selectiong a business college major: An analysis of criteria and choice using the analytical hierarchy process, Mid-American Journal of Business, 17 (2002) 47 56.

[18] A. Heiat, D. Brown, An empirical analysis of underlying factors affecting the choice of accounting major, Journal of College Teaching and Learning, 4 (2007) 83-98.

[19] S. Felton, N. Buhr, M. Northey, Factors influencing the business student's choice of a career in chartered accountancy, Issues in Accouting Education, 9 (1994) 131-141.

[20] J.G. Paolillo, R.W. Estes, An emperical analysis of career choice factors among accountants, attorneys, engineers, and physicians, The Accounting Review, 4 (1982) 785-793.

[21] B. Jackling, M. Keneley, Influences on the supply of accounting graduates in Australia: A focus on international students, Accounting and Finance, 49 (2009) 141-159.
[22] S. McGowan, L. Potter, The implications of the Chinese learner for the internationalization of the curriculum: An Australian perspective, Critical Perspectives on Accounting, 19 (2008) 181-198.

[23] I. Ajzen, M. Fishbein, Understanding attitudes and predicting social behavior, Prentice-Hall, Englewood Cliffs, NJ, 1980.

[24] J.F. Yates, E.S. Veinott, A.L. Patalano, Hard decisions, bad decisions: On decision quality and decision aiding., in: S.L. Schneider, J. Shanteau (Eds.) Emerging perspectives on judgment and decision research, Cambridge University Press, Cambridge, UK, 2003, pp. 1363.

[25] G. Morcol, Decision making: An overview of theories, contexts, and methods, in: G. Morcol (Ed.) Handbook of decision making, CRC Press, Taylor \& Francis Group, Boca Raton, FL, 2007, pp. 3-18.

[26] H.A. Simon, Models of my life, MIT Press, Cambridge, MA, 1996.

[27] M.G. Martinsons, Strategic decision making and support systems: Comparing American, Japanese and Chinese management, Decision Support System, 5 (2007) 158-177.

[28] Y.M. Chia, H.C. Koh, J. Pragasam, An international study of career drivers of accounting students in Singapore, Australia and Hong Kong, Journal of Education and Work, 21 (2008) 41-60.

[29] J. Davies, A taste of further education: The meaning of coming to college for a group of 14-16 year olds, in: BERA research student symposium, Exeter, UK, 2003.

[30] D.S. Easterling, K. Smith, A factor-analytic investigation of students perceptions regarding purpose, choice of major, and future work, Journal of College and Character, X (2008) 1-19.

[31] M. Bloomer, P. Hodkinson, Moving into FE: The voice of the learner, Further Education Development Agency, London, 1997.

[32] D. Gambetta, Were they pushed or did they jump? Individual decision mechanisms in education, Cambridge University Press, Cambridge, 1987.

[33] K.A. Goyette, A.L. Mullen, Who studies the arts and sciences: social background and the choice and consequences ofundergraduate field of study, The Journal of Higher Education, 77 (2006) 497-538.

[34] D.J. Scott, A.T. Church, Separation/attachment theory and career decidedness and commitment: Effectso f parental divorce., Journal of Vocational Behavior, 58 (2001) 328-347.

[35] J.E. Larkin, K.A. Laport, H.A. Pines, Job choice and career relevance for today's college students, Journal of Employment Counseling, 44 (2007) 86-95.

[36] M. Yang, What attracts mainland Chinese students to Australian higher education, SLEID, 4 (2007) 1-12. 